\title{
Que feminismo é esse que nasce na horta?
}

Maria Ignez Silveira Paulilo'

\section{Resumo}

Procuramos mostrar a necessidade de uma prévia adequação das teorias feministas para tentarmos explicar o feminismo que faz parte dos ideais do Movimento de Mulheres Camponesas (MMC), organização presente no Brasil desde 1983, que só se considerou feminista em 2010. É preciso evitar certo evolucionismo presente quando se compara campo e cidade. Para isso, o conceito de "transmodernidade" de Rodríguez Magda (2007) torna-se frutífero, porque não trabalha com noções evolucionistas do feminismo, mas diz que elementos de diferentes correntes, antigas e recentes, aparecem combinados nas atuais. A autora não considera as novas correntes mais "corretas" que as antigas, prefere falar das "ficções úteis" que mobilizam os movimentos e, portanto, são "reais". Para buscarmos essas "ficções úteis" será preciso revisão histórica das correntes que trouxeram elementos ao feminismo das agricultoras. Para explicar a prática das militantes, propomos o uso dos conceitos de "experiência", de Scott (1999), e de "experiência próxima" e "experiência distante", de Geertz (2003). Acreditamos que só depois de uma reflexão teórico metodológica focada no problema de pesquisa poderemos levar a cabo essa investigação.

Palavras-chave: Gênero. Feminismo. Mulheres rurais. Movimentos sociais rurais.

\section{Nota preliminar}

Este texto não é propriamente um artigo, é uma proposta de estudo para um fenômeno recentemente surgido no Brasil que é o "feminismo camponês". Sendo o feminismo um movimento muito urbano, enquanto a sociologia rural é uma disciplina que historicamente privilegiou a ideia de "família rural" como um todo unido, dando pouca atençáo às questóes de gênero, situação que felizmente vem se modificando, temos que as revistas feministas e as dedicadas ao campo, juntamente com seus leitores, dificilmente se cruzam. Publicar um texto feminista em um dossiê sobre agricultura familiar é uma tentativa de aproximar essas duas áreas de estudo.

I Professora da Universidade Federal de Santa Catarina e bolsista do CNPq. E-mail: ipaulilo@terra.com.br. 
Para quem conhece meus trabalhos, vai ficar claro que náo fui original neste texto, tendo me reportado a textos e pesquisas anteriores. Mas a proposta náo foi escrever um texto novo para leitores(as) feministas, mas sim me dirigir a um público novo, àqueles para quem as agricultoras ainda estáo um tanto invisíveis.

Acrescento também que a pesquisa sobre o que as participantes do Movimento de Mulheres Camponesas entendem por feminismo, e quais são suas principais reivindicaçóes quanto à menor desigualdade entre homens e mulheres, está apenas começando, motivo pelo qual náo trago dados de campo nessa "espécie de ensaio" que apresento aqui. O que trago são propostas teórico-metodológicas para dar seguimento à investigaçáo. Acompanho esse Movimento, surgido em 1983, desde o início dos anos 1990, e foi somente em 2010 que suas militantes passaram a usar publicamente a palavra feminismo em um encontro ocorrido na cidade de Xaxim, SC, encontro do qual participei e onde pude sentir de perto avanços, tensóes e impasses. Meu propósito ao publicar sobre feminismo em uma coletânea sobre o mundo rural e tentar fazer o caminho dos feminismos e dos estudos agrários se cruzarem, por isso, náo procurei profundidade nesta proposta de estudo, e sim amplitude, tentando sensibilizar os estudiosos do campo para o desafio que é ver tantas "pontas de fio" puxadas pelos feminismos e não as deixar soltas.

\section{Introdução}

Como diz Rodríguez Magda (2007, p. 139), filósofa, o tempo do feminismo correu depressa. O que é considerada a primeira onda do feminismo aconteceu no século XIX com o movimento sufragista. Ressurgido nas décadas de 1960 e 1970, em apenas 30 anos, o feminismo da igualdade se enfrentou com o feminismo da diferença, a pós-modernidade relativizou muitos fundamentos das duas correntes, surgiram questionamentos vindos dos pensamentos pós-colonial, multicultural, da globalização e do ciberfeminismo.

Não começamos este projeto citando Rodríguez Magda por acaso. Há em seu texto um conceito, cunhado por ela mesma, o de "transmodernidade", muito útil para o tema que vamos desenvolver, qual seja: "que feminismo é esse que está sendo construído pelo Movimento de Mulheres Agricultoras - MMC2?”. A citação será um pouco longa, mas necessária:

20 Movimento de Mulheres Agricultoras de Santa Catarina, consolidado em 1983, se manteve por muitos anos com o nome Movimento de Mulheres Agricultoras - MMA. Em 1995 uniu-se a uma coligação nacional 
[...] la Transmodernidad prolonga, continúa y transciende la Modernidad, es un retorno de algunas de sus líneas e ideas, acaso las más ingenuas, pero también las más universales. [...]. Pero es un retorno distanciado, irónico, que acepta su ficción útil. La Transmodernidad es el retorno, la copia, la pervivencia de una Modernidad débil, rebajada, light. La zona contemporánea transitada por todas las tendencias, los recuerdos, las posibilidades; transcendente e aparencial a la vez, voluntariamente sincrética en su "multicronia". [...] La Transmodernidad es lo postmoderno sin su inocente rupturismo, [...]. Su clave no es el post, la ruptura, sino la transubstanciación vaso comunicada de los paradigmas. [...] Es el abandono de la representación, es el reino de la simulación, de la simulación que se sabe real. I (RODRÍGUEZ MAGDA, 1989, p. 141-142, apud RODRíGUEZ MAGDA, 2007, p. 151-152).

O pensamento da autora vai mais longe, mas nós, pesquisadora de campo e não filósofa, temos de dar conta não de uma teoria geral, mas de explicar um recorte do mundo em que vivemos, ou seja, explicar as origens e os fundamentos do feminismo que passou a fazer parte dos ideais do Movimento de Mulheres Camponesas (MMC), organização presente no Brasil desde a década de 1980, em quase todos os Estados e com diferentes nomes, até unir-se sob a sigla MMC em 2004.

Desde 2001, segundo entrevista realizada com Isaura Conte (setembro de 2015), uma das líderes do movimento, este passou a fazer parte da Via Campesina, ajudando tal organização a criar bases nos Estados de Santa Catarina e Rio Grande do Sul. O termo feminismo só aparece em suas manifestaçóes públicas, em Santa Catarina, em 2010, na 11 a Assembleia do Movimento de Mulheres Camponesas, realizada na cidade de Xaxim- SC, com o tema "Mulheres Camponesas e Feministas", em que estivemos presente, embora a

formada por movimentos autônomos de mulheres rurais da maioria dos Estados brasileiros, a Associação Nacional de Mulheres Trabalhadoras Rurais (ANMTR). Em 2004, ao associar-se a Via Campesina, passou a denominar-se Movimento de Mulheres Camponesas (MMC). Seu histórico de lutas foi resumido pela própria liderança em documento de 2004. "[...] a história de luta do MMA/SC, marcada pela existência das mulheres agricultoras organizadas, vai desde a conquista de sair de casa e pensar sobre o seu destino, o reconhecimento da profissão de trabalhadora rural, formação e capacitação das dirigentes e das mulheres sobre seus direitos, lutas pelo direito à saúde pública e de qualidade, direitos previdenciários (aposentadoria, auxílio-doença, auxílio-acidente de trabalho, auxílio-invalidez, pensão de viúva (o), salário-maternidade), e a luta por um novo projeto de agricultura agroecológica, recuperando as sementes e sabedoria popular, buscando a preservação da biodiversidade" (MMC, 2004). Embora o texto citado seja de 2004, a postura ecológica ainda é a preocupação central das militantes, que, seguidamente, têm se manifestado contra transgênicos, reflorestamentos, agrotóxicos, falta de incentivo às produções orgânicas e poder político das grandes empresas produtoras de celulose, sementes hibridas e transgênicas, pesticidas e outros tipos de insumo considerados perigosos para o meio ambiente. Em 2010, assumiram publicamente uma postura feminista. 
discussão sobre o feminismo já estivesse em andamento entre as lideranças há alguns anos. Mas não foi um aparecimento tranquilo, sentia-se a tensão que a nova proposta trazia para as mulheres da base do movimento.

Não se pode falar de "feminismo", mas sim de "feminismos". Há diferentes correntes teóricas já reconhecidas e respeitadas. Como todo pensamento que apoia bandeiras de luta, é impossível evitar um forte componente normativo nas diversas teorias. $\mathrm{O}$ interessante de se analisar um movimento feminista em sua prática é ver como elementos de diferentes teorias se combinam na açáo. Por isso, a ideia de "transmodernidade" pode ser útil para evitarmos preconceitos, para náo cairmos na armadilha de hierarquizar as diferentes tendências, considerando algumas ingênuas ou ultrapassadas. Como diz a Rodríguez Magda autora citada, há a "ficção útil”, "a simulação que se sabe real" e a "transubstanciação vasocomunicada".

É isso que nos importa, procurarmos entender que "ficções úteis", quais ("quais" em vez de "que"? crenças, quais (quais?) ideias-força moveram o MMC em direção ao feminismo. Acompanhamos esse movimento de perto desde o início da década de 1990, participando de suas reuniôes e escrevendo sobre ele e, por isso, sabemos que caminho difícil foi esse. Quantos anos e quantos debates se passaram até que o adjetivo "feministas" aparecesse publicamente junto com a expressão "mulheres camponesas".

Vamos reconstituir um pouco as principais subdivisóes ou dilemas do movimento feminista e apontar alguns entrecruzamentos, similaridades e, principalmente, impasses. Antes, porém, é preciso salientar a grande influência dos feminismos anglo-saxóes no mundo, inclusive no feminismo francês. Também é preciso lembrar que Vandana Shiva, feminista indiana muito reconhecida, escreve em inglês. Outra ressalva é que as divergências entre as posturas abaixo não são excludentes. Por exemplo, o "feminismo da igualdade" também é visto como "feminismo liberal". Cada item a seguir comporta discussóes imensas, mas vamos nos ater aos limites de um pequeno artigo.

\section{Feminismos e suas principais divergências}

\section{I Feminismos da igualdade, da diferença e radical}

O chamado "feminismo da igualdade" se esforçou muito para garantir às mulheres o mesmo direito atribuído aos homens. Um exemplo muito citado 
é a luta das sufragistas pelo voto. Mas não termina aí. Não podemos esquecer, por exemplo, que, no Brasil, as mulheres só alcançaram a igualdade plena de direitos com a Constituiçáo de 1988, quando o "pátrio poder" deixou de ser privilégio masculino. Esse movimento é herdeiro das ideias iluministas e, por isso, é apoiado ou criticado dependendo da importância dada ao Iluminismo como inspirador ou não da igualdade entre homens e mulheres. Embora não restem dúvidas que a igualdade entre os homens, e não entre homens e mulheres, foi o maior fruto da ilustração, feministas como Célia Amorós (2000), Amelia Valcárcel (2009) e Maria José Guerra Palmero (2001) consideram injusto não dar o devido valor a esse período histórico de explosão na busca por justiça e igualdade. Guerra Palmero diz que o Iluminismo foi roubado das mulheres; já Valcárcel menciona que o feminismo é um filho náo desejado do Iluminismo. Todas dão grande valor às pioneiras iluministas: Olympe de Gougese Mary Wollstonecraft.

O feminismo da diferença enfatiza as especificidades do ser feminino, principalmente quanto à capacidade de conceber, de "dar a vida". Critica o feminismo da igualdade para além dos argumentos teóricos e filosóficos, dizendo que essa linha de luta levou as mulheres a duplas jornadas de trabalho, ou triplas quando militam. Grande defensora dessa corrente, no Brasil, é Rosiska de Oliveira (1992).

O feminismo da diferença se desenvolveu na Itália e, principalmente, na França. Há muitas posiçóes intermediárias, não tratadas aqui. As posturas mais extremas são as que consideram que todo o conhecimento, inclusive a ciência, é machista e as mulheres teriam que recriá-lo. Na sociologia, essa posição é defendida, entre outros, por Pamela Abbott e Claire Wallace (1997).

Mais radical, Victoria Sandón de León tem provocado polêmicas com sua ideia de retornar ao mundo das deusas, defendendo que existiram sociedades matriarcais na antiguidade que eram mais justas e igualitárias que as que se seguiram. O ponto de mudança foi a descoberta da agricultura pelas mulheres, atividade que terminou por limitar o mundo feminino, na medida em que sedentarizou as antigas tribos. Se, para Léon, a descoberta da agricultura é o ponto de náo retorno para um mundo que subordina as mulheres, para as agricultoras do MMC, esse é o maior triunfo feminino, pois foram as mulheres que, além de dar à luz novos seres humanos, descobriram como alimentá-los de forma contínua. 
Com frequência, as defensoras da diferença (entre outras, Delphy, le Doeuff, Leclerk, Kristeva e Irigaray) são consideradas autoras muito abstratas, pouco vinculadas à realidade das mulheres, mantendo tênue vinculação com as lutas feministas. Linda Nicholson (2000, p. 20) faz uma crítica interessante ao feminismo da diferença, mesmo sem negar sua importância enquanto forma de chamar a atenção para a invisibilidade das desigualdades de gênero, no sentido de que ele tende para um "feminismo da uniformidade", visto que, para serem diferentes dos homens genericamente, as mulheres necessitam possuir características que as igualem, algo parecido com uma "essência", mesmo que se admita alguma influência da sociedade na formaçáo das distinçóes sexuais. O perigo maior é que na caracterização dessa "natureza" ou "essência", inevitavelmente estâo imbricados os valores da sociedade ou grupo dominante que as definem, daí o surgimento de um "feminismo europeu", branco, heterossexual e de classe média contra o qual se insurgiram as mulheres negras, lésbicas, pertencentes às classes trabalhadores e ao Terceiro Mundo.

Nem sempre as feministas que propóem políticas diferenciadas para as mulheres, como sistema de cotas, créditos especiais, entre outras, fazem isso porque acreditam que as mulheres são essencialmente diferentes, mas sim porque a tradicional subordinaçáo em que viveram e ainda vivem lhes dá poucos recursos para saírem dessa situação contando apenas com suas iniciativas. O feminismo surgiu e cresceu através das reuniôes de mulheres com mulheres e isso foi importante. Céli Pinto (1992) recupera a importância do "gueto". Porém, na medida em que políticas diferenciadas, seja por sexo, cor ou outra clivagem, entram em choque com uma ideia radical de igualdade, provocam polêmicas acirradas, haja vista o artigo de Scott (2001), que escreve do "ponto de vista da raiva”, contra as ideias da democracia radical de Mouffe (1996).

$\mathrm{O}$ feminismo das agricultoras do MMC defende a ideia de diferença entre homens e mulheres, porém, é um feminismo colado às lutas que desenvolvem. Para Vandana Shiva e Maria Mies (1997), e essa é uma autora que está começando a ser citada pelas agricultoras, as mulheres são essencialmente diferentes dos homens. Para Bina Argawal (1994), os valores femininos entre as mulheres rurais surgem do seu cotidiano e não de sua essência por ser mulher. Enquanto as feministas da igualdade temem que defender a diferença seja reforçar a visão tradicional da mulher enquanto mais ligada à natureza, sendo o homem mais ligado à cultura e à razáo, juntando a subordinação da 
natureza à subordinação da mulher, as agricultoras, tendo uma visão religiosa da natureza, considerando-a "sábia" e "boa", não veem a ligação mulher/ natureza como desabonadora (PAULILO, 2010). Beatriz E. Cid e Javiera S. Hinrichs (2015) trazem é "trazem" mesmo uma conclusão interessante sobre uma rede de mulheres do centro sul do Chile que defendem as sementes crioulas. Embora defendam posições essencialistas, ou seja, sustentam que há uma ligação inata entre mulher e natureza, suas açóes levam a mudanças antiessencialistas que desafiam os papéis sexuais tradicionais.

O feminismo radical é o que nos interessa menos porque pouco tem a ver com os valores do MMC. Quando há alguns pontos de semelhança, esses pontos se localizam nas intersecçóes entre as outras correntes do feminismo, a liberal, a da diferença e a socialista. As pensadoras Kate Millete e Shulamith Firestone são as mais conhecidas desta vertente (SÁNCHEZ; BÉLTRAN; ALVARES, 2005, p. 75-125). Para elas, a opressão sexual corta transversalmente toda a sociedade e o patriarcado é uma categoria mais explicativa que regimes políticos e econômicos, porque as mulheres são oprimidas apenas por serem mulheres. Póe em questão a família tradicional nuclear, a heterossexualidade e a própria reprodução como formas de dominação. Uma das propostas mais polêmicas desta corrente é que a gestaçáo se dê fora do corpo da mulher, através do avanço das tecnologias reprodutivas.

\subsection{Feminismo essencialista $\mathcal{E}$ feminismo construcionista}

São consideradas essencialistas as feministas que creem existir uma ligação inata, essencial, entre mulheres e natureza. Vandana Shiva e Maria Mies (1997) são as defensoras mais mundialmente conhecidas dessa postura. Para as construcionistas, as diferenças entre os dois sexos são muito mais uma construção social que legitima a dominação masculina. Defender que há uma "essência feminina” seria correr o risco de reforçar e perpetuar essa dominação.

É interessante como, nesse binômio mulher/natureza, as correntes que veem a mulher, bem como o homem, como sendo uma construção social, elaboram variados níveis de desconstrução do que é tido como feminino ou masculino, chegando até a posturas radicais como a teoria "queer" de Judith Buttler (1990), segundo a qual não só o gênero, mas o próprio sexo é construído. Para essa autora, a representação do que deve ser entendido como matéria (natureza, corpo, sujeito, etc.) é anterior à matéria, porque o que a 
regulamenta é o discurso que a constrói que, ainda, naturaliza essa construção (FEMENÍAS; SPADARO, 2004, p. 237). Porém, a ideia de natureza é menos discutida. Ora ela é vista como imutável em suas leis de funcionamento mais profundas e, ao mesmo tempo, como "sábia", ora ela é vista como estando à disposição dos homens, de sua ciência e de sua técnica. Os defensores das duas concepçóes veem seu entendimento como sendo o "verdadeiro".

A grande influência do pós-modernismo e sua ideia de desconstrução tiveram tanta força no pensamento acadêmico que muitas feministas reagiram ao que consideraram uma "desconstrução sem fim", que não suporta qualquer bandeira de luta, embora não neguem a importância de se procurar as raízes machistas das ideias consideradas universais. As grandes contribuiçóes do pós-modernismo para o feminismo foram: a) questionamento sobre a objetividade e neutralidade da razão e da ciência; b) afirmação de que o poder está difundido pela sociedade, não se concentrando apenas no Estado; c) ênfase na diferença, favorecendo o aparecimento de movimentos feministas entre grupos marginalizados, como de negras, lésbicas, entre outros.

A influência do pós-modernismo e da ideia de desconstrução aumentou muito, nos últimos anos, entre as feministas acadêmicas, mas o mesmo não aconteceu entre as militantes de movimentos de base como o MMC. Contribuiu também, para isso, a passagem da denominação "estudos da mulher" para "estudos de gênero". Falaremos disso mais adiante. É um duro exercício para nós, feministas com forte influência desconstrucionista, analisar, sem preconceitos, o essencialismo do MMC.

A convivência das duas posturas tem se mostrado táo difícil como a que se estabeleceu entre o feminismo da igualdade e o feminismo da diferença. Cecile Jackson (1993), ao publicar em periódico tão respeitado quanto o The Journal of Peasant Studies, critica o ecofeminismo de base essencialista dizendo que a celebração de uma distinçáo biológica entre homens e mulheres, considerando-as mais próxima da natureza, leva a uma representação das mulheres como sub-humanas e serve de suporte a posturas reacionárias, além de igualar todas as mulheres. Não é isso que se vê como resultado da luta das mulheres agricultoras. Nessa mesma direção, ou seja, criticando a dicotomização entre as duas posiçóes, Linda Nicholson (2000, p. 15) menciona que não basta "reconhecer qualquer distância em relação ao determinismo biológico para se evitar todos os problemas associados a essa posição". 


\subsection{Mulher E gênero}

Ao lermos o livro de Deere e Léon (2002) - O empoderamento da mulher - concordamos com a afirmação de que os estudos feministas na América Latina têm se centrado mais em questôes de identidade e reconhecimento, especialmente direitos reprodutivos e violência contra a mulher, deixando em segundo plano os problemas relacionados aos direitos de propriedade e distribuição de renda.

Os estudos sociológicos sobre as condições da mulher no Brasil começaram na Sociologia do Trabalho, com ênfase nas operárias. Falava-se, entáo, em Sociologia da Mulher, bem como Antropologia da Mulher. A introdução do termo "gênero" começou no início dos anos 1990, sendo reforçada depois da traduçáo para o português do texto de Joan Scott (1990) - Gênero: uma categoria útil de análise.

O que primeiro chama a atenção no termo "gênero" é o que ressalta Portulés (2007). Se, em inglês, esse termo está associado aos conceitos de sexo, sexualidade e diferença sexual, o mesmo náo acontece, segundo a autora, no francês, no italiano e no espanhol. Acrescentamos que também não acontece no português. Essa especialidade da língua inglesa e sua ampla aceitaçáo reforça o já dito, a grande influência mundial do feminismo anglo-saxão.

É inegável a importância do conceito de gênero na desconstrução das bases biológicas que sustentavam a inferiorização da mulher, por ter mostrado o papel imprescindível da cultura na criação das relaçóes de poder. Porém, o relativismo do conceito levou a uma despolitização do feminismo acadêmico, ao mesmo tempo em que a uma apropriaçáo do conceito de gênero por parte dos Estados e órgão oficiais de desenvolvimento, nacionais e internacionais. Surgem então os "estudos de gênero"alheios ao feminismo, cuja falta lhes tira algo de muito importante: seu caráter emancipatório ${ }^{3}$.

Além de uma despolitização útil para atenuar a contundência das reivindicaçôes feministas, o termo "gênero" se adequa mais às críticas à heterossexualidade e às reivindicaçóes dos movimentos homossexuais que a busca

3 Há mais feministas preocupadas com a despolitização que o conceito de "gênero" provocou entre os estudos sobre mulheres. Cito apenas Claudia Lima Costa (1998) e Sonia Alvarez (1990), a primeira devido à discussão teórica, e a segunda, por sua larga experiência junto a órgãos internacionais oficiais. 
por equidade econômica (PORTOLÉS, 2007). Quando a reivindicação principal do movimento não depende da desconstruçáo da própria ideia de sexo, um "essencialismo estratégico", como quer, entre outras, Susan Bordo (1989 apud PORTOLÉS, 2007), ou uma "ficção útil”, como diz Rodríguez Magda (2007), permite que as mulheres se construam como um coletivo e que suas lutas avancem. Essas autoras que se consideram "essencialistas de vez em quando" (PORTOLÉS, 2007) compartilham da ideia do perigo de uma desconstrução sem fim. Acreditamos que a relevância dos estudos sobre sexualidade na América Latina tenha levado o conceito de gênero para além de sua utilidade estratégica para outras áreas.

\subsection{Feminismo liberal e feminismo socialista}

O feminismo liberal assemelha-se ao feminismo da igualdade, busca garantir às mulheres os mesmos direitos dados aos homens, dentro do Estado liberal. Já o feminismo socialista propóe uma mudança da sociedade existente, no sentido de maior igualdade não só entre os sexos, mas entre classes, raças e etnias, apostando em mudanças econômicas radicais como a superaçáo do capitalismo. O feminismo presente entre as militantes do MMC tem muita influência das ideias socialistas, mas também conta com a possibilidade de criação de leis mais favoráveis às mulheres na sociedade atual.

A convivência entre as duas correntes está longe de ser tranquila. Durante o sufragismo, muitas operárias, ligadas a grupos socialistas ou anarquistas, não viam sentido nessa reivindicação "burguesa" de poder votar e ser votada (BÉLTRAN et al., 2005). As teóricas socialistas sempre tinham que se debater entre a ortodoxia e os interesses específicos das mulheres. Alexandra Kolontai, líder socialista durante a Revolução Russa e o início da implantação do comunismo soviético, além de pregar o amor livre, o salário igual, a legalização do aborto, a socialização dos cuidados com a casa e filhos, enfrentava questóes ligadas à sexualidade das mulheres como parte fundamental de sua identidade (BÉLTRAN et al., 2005, p. 62-63; KOLONTAI, 2005).

O grande dilema dos socialistas foi (e ainda é) a questão de quem cuida da casa e da prole. As propostas sempre passaram por soluçóes coletivas, incluindo, inclusive, o fim da família nuclear. É interessante ver, em um nascente socialismo feminista camponês, como fica essa questáo onde o trabalho é familiar, longe, portanto, do trabalho assalariado capitalista e das fazendas 
coletivas dos países comunistas. Talvez seja até excessivo repetir que a ênfase na missão histórica do proletariado - enquanto agente principal da revolução socialista - levou, entre os seguidores do marxismo mais clássico, a poucas teorizaçôes sobre outras formas de produção, entre elas a camponesa, ressaltando apenas sua condição subordinada ao capitalismo.

O feminismo socialista brasileiro foi muito forte nas décadas de 1970 e 1980 e, devido à influência que teve das ideias de Karl Marx e seus seguidores, é chamado mais comumente de feminismo marxista. Nele, o conceito de "classe social" tinha um papel fundamental. Quando se estudavam as mulheres da classe operária, havia poucos impasses teóricos. Porém, ao estudarmos as mulheres do campo usando as mesmas categorias teóricas um tanto rígidas da época, nem sempre as especificidades do que hoje chamamos de "modo de vida camponês" ficavam claras. Enfatizava-se mais a subordinação e a apropriação do sobretrabalho das famílias rurais pelo modo de produção capitalista.

O feminismo brasileiro, salvo algumas exceçóes, foi, pouco a pouco, afastando-se das teorias marxistas, principalmente depois da "virada linguística", quando a ideia de "desconstrução" nas ciências sociais começou a ter um papel bastante forte. Também a consciência de que as ciências são uma forma de conhecimento interpretativa e náo exata, que sem dúvida é de imensa importância, levou, equivocadamente, a se considerar qualquer interpretação dos fenômenos sociais como sendo táo válida como tantas outras, levando a que algumas pesquisas não se distanciassem do nível do senso comum. O senso comum interpreta, a ciência também, mas não a partir das mesmas bases. Se a ciência não tem aquela exatidão tão valorizada, nem por isso perdeu seu lugar enquanto uma das formas importantes de conhecimento sobre o mundo, embora não a única.

Náo deixa de ser interessante que, enquanto o feminismo urbano afasta-se da ideia de classe social, o feminismo praticado pelo Movimento de Mulheres Camponesas considera esse conceito fundamental. Apenas como exemplo, cito o título Seminários Conexóes IV: feminismo, campesinato e luta de classes, dado ao encontro ocorrido em Brasília-DF (UnB), no período de 15 a 17 de setembro de 2014, e promovido pelo grupo de pesquisa "Modos de Produçáo e Antagonismos Sociais (MPAS)", em parceria com o curso Residência agrária: matrizes produtivas da vida no campo, a Escola Nacional Florestan Fernandes 
(ENFF), o Movimento de Mulheres Camponesas (MMC), o Movimento dos Pequenos Agricultores (MPA), o Movimento dos Trabalhadores Rurais Sem-Terra (MST), e a Via Campesina.

Um dos poucos momentos em que se percebe um retorno à ideia de classe nas correntes feministas urbanas é entre aquelas ligadas ao estudo do care, ou seja, "cuidado" em português. Nada de estranho, já que, no cerne dessa problemática, está a questão do "trabalho", a de quem vai cuidar de crianças, enfermos e idosos. E, quando se fala em trabalho, a desigualdade sempre está presente. Afinal, a responsabilidade por esse tipo de tarefa é sempre das mulheres, sejam elas mães, esposas, filhas, noras ou empregadas domésticas. Um bom exemplo do uso do conceito de "classe" ligado a gênero e aos cuidados são os artigos da Revista de Sociologia da USP, Tempo Social (2014).

Os estudos sobre care estão tendo grande impulso na França. Porém, as diferenças na situação da Europa Ocidental e a do Brasil tornam as pesquisas de difícil comparação. Enquanto no velho mundo as mulheres estão podendo contar com ajuda no trabalho doméstico dada a grande presença de migrantes pobres (HIRATA et al., 2007), em nosso país o emprego doméstico vem se tornando mais dispendioso para as patroas e, portanto, menos frequente, dada a profissionalizaçáo das empregadas. Comparar com a situação das agricultoras familiares é ainda mais inócuo porque elas dificilmente contam com auxílio doméstico remunerado, sendo mais comum a ajuda de filhas, noras ou sogras.

Nancy Folbre (2012) também fala sobre o aumento do número de empregadas domésticas nos Estados Unidos, principalmente por causa da presença das imigrantes de países mais pobres, o que resulta em maior ajuda às esposas norte-americanas no que se refere aos cuidados da casa e dos filhos. Dada a situação de pobreza e ilegalidade em que vivem as imigrantes, não é raro que sejam contratadas em situaçóes under-the-table, nas palavras da autora, ou seja, de maneira irregular, sem direitos trabalhistas e por um salário pequeno. Aqui, novamente, a comparação com o Brasil fica difícil, pois o governo brasileiro vem fazendo um esforço no sentido de regularizar o trabalho das domésticas, o que aumenta o gasto com encargos trabalhistas por parte das patroas. Em longo prazo, podemos ter uma diminuiçáo do número de domésticas e não um aumento. 
Há ainda outra questão central que o feminismo socialista enfrenta: qual a importância do conceito de "patriarcado". A forte influência do marxismo nos primórdios do feminismo brasileiro, fez com que esse conceito náo tivesse a relevância que teve em países do Norte. Um texto emblemático é o de Elisabeth Souza Lobo (1992), que continua na tradição do livro clássico de Saffioti (1969) - A mulher na sociedade de classes -, no qual a autora reconhece a subordinação milenar da mulher, mas se detém mais na análise das formas de como o capitalismo se apropria dessa subordinação e não na sua origem histórica. Lobo é enfática quando diz que é um falso problema procurar a causa original da subordinação feminina. $\mathrm{O}$ importante é pesquisar como essa subordinação das mulheres se construiu historicamente, nas práticas, nas culturas e nas instituiçóes. Procurar essa causa original na existência ancestral do patriarcado traria mais problemas que soluçóes.

As militantes do MMC usam o termo "patriarcado" não como explicação da subordinação feminina, mas como algo tradicional que é difícil mudar como o são todas as tradiçóes. Do patriarcado, cuja origem se perde no passado, deriva o machismo, forma cotidiana de dominaçáo exercida pelos homens sobre as mulheres. Porém, creem que, aos poucos, com luta, a mudança é possível. Citam como inspiração as transformaçóes que já ocorreram desde o tempo de suas máes e avós.

\subsection{Um feminismo latino-americano?}

Algo que sempre nos chamou a atenção foi a ausência do Brasil em livros publicados em outros países sobre mulheres rurais na América Latina. A impressão que se tem é que só a América hispânica é considerada latina; a portuguesa, não. Por isso, foi com surpresa e alegria que vi citado, no artigo de Raewyn Connell (2014), o livro A mulher na sociedade de classes, de Heleieth I. B. Saffioti (1969), obra de enorme importância para o feminismo brasileiro, tanto pela densidade do estudo quanto pelo momento em que surgiu.

Nunca encontramos uma boa explicação, só pistas. Na Inglaterra, uma feminista me disse que o Brasil não era terceiro mundo porque não era tão pobre; outros me disseram da dificuldade de ler português. Isso náo seria problema se as obras de nossas principais feministas fossem traduzidas. Também o fato de nosso campesinato não ser marcantemente de origem indígena, com exceção de algumas regióes do Norte, parece influenciar. Mais recentemente, 
temos observado que, quanto ao nosso país, é comum autoras estrangeiras citarem apenas os escritos de Sônia Alvarez, cubana que fez carreira nos Estados Unidos, escreve em espanhol e inglês e esteve um período no Brasil. Ou citam os trabalhos conjuntos de Carmen Deere, americana de família porto-riquenha, e Magdalena León, equatoriana, que incluem o Brasil em suas obras e escrevem em espanhol e inglês. Percebemos uma mudança quando foram publicados os volumes do Perfiles del feminismo ibero-americano, organizados pela argentina María Luisa Femenías (2005, 2007). A autora manteve a mesma postura em obra posterior (FEMENÍAS; SOZA ROSSI, 2011). Aí começam a aparecer autoras brasileiras, especialmente as que escrevem em espanhol ou inglês.

Estando em Montevidéu em um congresso no mês de julho de 2013, percorremos as livrarias em busca de novas obras. Percebemos que, na literatura feminista publicada em língua espanhola, há um movimento de construção de um feminismo latino-americano em contraponto ao dos países do Norte. No último volume da Revista de Estudos Feministas (CYPRIANO, 2013), há um artigo de Breno Cypriano - Construçóes do pensamento feminista latino-americano-, em que o autor também trata do tema. Encontramos a coletânea organizada por Karina Bidaseca e Vanesa V. Laba (2011) - Feminismo y postcolonialidad: descolonizando el feminismo desde y en America Latina-, um livro de 480 p. Também encontramos, traduzido do inglês para o espanhol, o livro de Maxime Molineux (2003) - Movimiento de mujeres en America Latina: estudo teórico comparado - em que são citados vários trabalhos de Sônia Alvares, mas as únicas feministas brasileiras que reconhecemos foram Carmen Barroso, em um artigo de 1987, publicado em espanhol, e Teresa Caldeira, em texto de 1990, publicado em inglês. Toda a riqueza da década de 1990, no Brasil, portanto, está pouco explorada.

No Brasil também há produção feminista, escrita em português, que se propóe a construir abordagens menos carregadas de influências dos países do Norte como, por exemplo, Marlise Matos (2010), Sartori, Santos e Silva (2015), bem como autores como Marcelo Rosa (2014), que apontam limites para essas novas propostas. Porém, em andanças por congressos na América Latina, percebe-se com mais força a defesa de uma produção fora do eixo euro-américa em publicações em língua espanhola que em português. 
O que nos atrai na aproximação entre o MMC e o feminismo é o caráter prático do movimento. Se, por um lado, há imensas pirâmides teóricas construídas para dar conta, seja do caráter universal das mulheres, seja da multiplicidade de diferenças que impedem o uso não só do termo "mulher", mas até o de "mulheres", as agricultoras estão tentando trazer princípios feministas para o seu cotidiano. Chama a atenção como um movimento feminista tardio, como é o do MMC, resgata traços de correntes feministas que perderam força nos últimos anos, como a liberal e a socialista. Acentua a ideia de essência quando a desconstrução impera quase hegemônica nas academias e movimentos homo e transexuais. Vai contra a corrente do niilismo e da concepção da sociedade dividida em "tribos" para recuperar ideias de igualdade que nada devem ao Iluminismo. Defende a importância da "vida" e de "dar a vida” em um momento em que o direito ao aborto faz parte da maioria das pautas feministas.

Por mais que se tente negar, há um evolucionismo implícito, presente tanto nos movimentos sociais quanto em grande parte das teorias que os analisam. Ouve-se comentários de militantes afirmando que a aceitação do aborto é uma questão de tempo e amadurecimento. Seria mesmo? Isso não levaria ao pressuposto de que os movimentos que não o defendem teriam que "evoluir"? Enquanto os perigos do essencialismo sáo ressaltados, pouco se fala no perigo do evolucionismo, mesmo quando o ponto de chegada dessa evolução seja duvidar de qualquer ponto de chegada.

O feminismo tem uma marca urbana muito forte, mas mesmo os movimentos feministas brasileiros de caráter urbano são pouco explorados nos estudos sobre a América Latina. Isso leva-nos a temer que uma aproximação táo importante dos movimentos de mulheres rurais com as ideias feministas, mesmo o MMC sendo ligado a um órgáo internacional como a Via Campesina, passe despercebido. Que passe despercebido mesmo depois que, em 2006, no sul do Brasil, militantes da via Campesina de Santa Catarina e Rio Grande do Sul destruíram um laboratório de mudas da Aracruz Celulose (PAULILO; MATIAS, 2006). Consideramos de grande importância a contribuição das agricultoras brasileiras para desurbanizar as pautas, para levar o mundo a discutir a soberania alimentar, a se preocupar com a distribuição masculina e concentrada da terra e outras questôes mais. Se as mulheres rurais demoraram a se aproximar das correntes feministas, estas últimas também dificilmente as 
veem como contribuintes do movimento feminista, mas sim como mulheres que precisam ser "acordadas", ensinadas e conduzidas por esse movimento.

Como compreender esse feminismo que "nasce na horta" tem sido para nós uma preocupação constante. Temos a nosso favor o fato de nos considerarmos feministas desde o início da década de 1970, época em que o feminismo marxista era muito forte não só no Brasil, como também na América Latina. Sendo assim, as questôes de classe e de desigualdade na distribuição da renda e da propriedade nos são familiares. Percebo, nas feministas mais jovens, não agricultoras, uma distância grande em relação a esses temas. No esforço de elaborar procedimentos que nos ajudem nessa compreensão, em artigo anterior expusemos os autores que nos servem de inspiração. Reproduzimos aqui os pontos principais.

Joan Scott (1999, p. 27), em seu texto "Experiência", trouxe-nos a ideia de que "[...] náo são os indivíduos que têm experiência, mas os sujeitos é que são constituídos através da experiência”. Para essa autora, não há um ponto de chegada pré-determinado, a experiência vai constituindo as identidades e visões de mundo que, como mostra a história, estão em constante mutação. Como os grupos sociais, entre eles as mulheres, se veem relaciona-se com o que estão vivenciando. $\mathrm{O}$ trabalho de Scott reforça a necessidade de aproximaçáo com as correntes da hermenêutica, no sentido da importância da "compreensáo" enquanto elemento fundamental de inteligibilidade das práticas sociais.

Clifford Geertz e Anthony Giddens alertam os pesquisadores para que não se iludam quanto à sua identificação com o grupo estudado, por mais simpatia que tenham pelas ideias de que seus participantes são portadores. Em O saber local, Geertz (2003) diferencia a "experiência próxima" da "experiência distante". Ele desconfia da possibilidade do investigador de colocar-se "debaixo da pele do outro", alertando que, como qualquer um de nós, os outros também "preferem considerar suas almas como suas".

Por fim, Anthony Giddens (1978) reforça nossas convicçóes e as esclarece quando diz que a posiçáo relativista começa com um postulado universal (tudo é relativo) e só termina com a descoberta de que todo conhecimento se move em círculo e, para ultrapassar o relativismo de julgamento, é necessário sustentar uma distinção entre sentido e referência em relação aos quadros de significância. Ele retoma a importância da teoria e a importância dos conceitos 
construídos pelo pesquisador (e não total submissão à fala dos entrevistados), dizendo que as ciências sociais podem empregar legitimamente conceitos que não são necessariamente familiares àqueles a cujo comportamento esses conceitos se referem (PAULILO, 2010, p. 937-938).

\section{Conclusões}

Ao estudarmos os feminismos presentes no mundo, não levar em conta a importância dos movimentos de mulheres agricultoras na busca de maior equidade social, não só do Brasil, é uma lacuna grave. Entre suas açóes está a defesa do uso de sementes crioulas e de uma forma de produzir alimentos saudáveis em um momento em que há uma grande expansão das culturas transgênicas e um monopólio gritante das empresas multinacionais na produção de sementes. Também esses movimentos têm trazido à tona, novamente, questóes de classe, do caráter oligopolista dos mercados, questóes de pobreza, de miséria mesmo, da fome no mundo que ficaram um pouco perdidas entre algumas correntes mais abstratas do feminismo. Também a luta das agricultoras tem sido uma luta muito colada às suas práticas cotidianas, está inserida em um "mundo da vida" e, talvez por isso, nem sempre os conceitos que foram cunhados ao longo de muitas décadas de hegemonia dos feminismos urbanos conseguem dar conta de explicar o alcance e o sentido de suas metas e conquistas.

Resumindo e reforçando o que estamos propondo, a ideia central é abandonar qualquer resquício de evolucionismo que privilegie os feminismos urbanos frente aos rurais. A categoria teórica "transmodernidade", em boa hora trazida por Rosa Maria Rodríguez Magda, é mais útil para nossos estudos que os conceitos de "alta modernidade" ou "ultra modernidade", ou mesmo "pós-modernidade", sem que, por isso, precisemos descartá-los. Por tanto tempo se acreditou no desaparecimento dos camponeses, que se transformariam em empresários familiares ou proletários nos países capitalistas ou, então, trabalhadores em fazendas ou agroindústrias coletivas, nos socialistas, que é preciso uma vigilância constante para evitar pensá-los em termos de um futuro imaginado e idealizado, ou seja, em pensá-los como carentes ainda de algum tipo de "evolução".

Como o feminismo camponês é um feminismo que vem da prática cotidiana, próximo do que mostrou Bina Argawal para a Índia, consideramos 
que usar o conceito de "experiência" de Joan Scott seria uma boa maneira de evitarmos considerar que é preciso haver um "ponto de chegada" para a ação das mulheres rurais serem consideradas "corretas" em termos de feminismo. Com isso, novamente se tentar evitar o evolucionismo, ao mesmo tempo em que se enfatiza mais os caminhos percorridos e as estratégias usadas por elas, que padróes desenvolvidos e aceitos em outros tipos de contextos.

Clifford Geertz nos previne contra a tentação de querermos ser "mais realistas que o rei”, ou seja, mais camponesas que as mulheres rurais ou, pelo menos suas iguais, julgando-as mais do que as compreendendo. Anthony Giddens nos deixa livre para irmos além das descriçóes, sempre importantes, e procurarmos em conceitos como o de "transmodernidade" uma possibilidade heurística.

\section{Referências}

ABBOTT, P.; WALLACE, C. An Introduction to Sociology. 2 ed. London; New York: Routledge, 1997.

ALVAREZ, S. Engendering Democracy in Brazil: Women's Movements in Transition Politics. Princeton, USA: Princeton University Press, 1990.

AMORÓS, C. Tiempo de feminismo. Madrid: Ediciones Cátedra; Universitat de València; Instituto de la Mujer. 2000.

ARGAWAL, B. A field of one's own: tender and land rights in South Africa. New York: Cambridge University Press, 1994.

BELTRÁN, E.; MAQUIERA, V.; ALVAREZ, S.; SÁNCHEZ, C. (Ed.). 2. ed. Feminismos: debates teóricos contemporâneos. Madrid: Alianza Editorial, 2005.

BIDASECA, B.; LABA, V. (Ed.) Feminismos y postcolonialidad: descolonizando el feminismo desde y en América Latina. Buenos Aires: Ediciones Godot, 2011.

BUTLER, J. Gender Trouble. New York: Routledge, Chapman \& Hall, 1990.

CID, B.; HINRICHS, J. Curadoras de semillas: entre empoderamento y esencialismo estratégico. Revista de Estudos Feministas, v. 23, n. 2, p. 347-370, 2015.

CONNELL, R. The sociology of gender in Southern perspective. Current Sociology Monograph, v. 62, n. 4, p. 550-567, 2014. 
COSTA, C. de L. O tráfico do gênero. Cadernos Pagu, n. 11, p. 127-140, 1998.

CYPRIANO, B. Construçôes do feminismo latino-americano. Revista de Estudos Feministas, v. 21, n. 1, p. 11-39, 2013.

DEERE, C.; LEÓN, M. O empoderamento da mulher. Porto Alegre: Ed. da UFRGS, 2002.

FEMENÍAS, M. L. Perfiles do feminismo ibero-americano. Vol 2. Buenos Aires: Catálogo, 2005

Perfiles do feminismo ibero-americano. Vol. 3. Buenos Aires: Catálogo, 2007.

.; SOZA ROSSI, P. (Org.). Saberes situados/Teorias trashumantes. La Plata: Fundación de la Facultad de Humanidades y Ciencias de La Educación de La Universidad Nacional de La Plata, 2011.

.; SPADARO, M. C. Ecopasividad o ecofeminismo? In: CAVANA, PULEO; SEGURA (Org.). Mujeres y ecologia. Madrid: A. C. Al-Mudayna, p. 233-241, 2004.

FOLBRE, N. WHO CARES? A feminist critique of the care economy. New York: Rosa LuxemburgStiftung, 2012.

GEERTZ, C. O saber local. Petrópolis: Vozes, 2003.

GIDDENS, A. Novas regras do método sociológico. Rio de Janeiro: Zahar Ed., 1978.

GUERRA PALMERO, M. J. Teoria feminista contemporánea. Madrid: Editorial Complutense, 2001.

HIRATA, H.; KERGOAT, D. Novas configuraçóes da divisão sexual do trabalho. Cadernos de Pesquisa, São Paulo, v. 37, n. 132, p. 595-609, 2007.

JACKSON, C. Women/nature or gender/history? a critique of ecofeminist development. The Jornal of Peasant Studies, v. 20, n. 3, p. 389-418, 1993.

KOLONTAI, A. A nova mulher e a moral sexual. 3. ed. São Paulo: Expressão Popular, 2005.

LOBO, E. S. O trabalho como linguagem: o gênero do trabalho. In: COSTA, A. de O.; BRUSCHINI, C. Uma questáo de gênero. Rio de Janeiro: Rosa dos Ventos; São Paulo: Fundaçáo Carlos Chagas, 1992. p. 252-265.

MATOS, M. Movimento e teoria feminista; é possível reconstruir a teoria feminista a partir do Sul global?. Revista de Sociologia Política, v. 18, n. 36, p. 67-92, 2010.

MOLINEUX, M. Movimientos de mujeres em América Latina: estúdio teórico comparado. Madrid: Ediciones Cátedra; Universitat de València; Instituto de la Mujer, 2003. 
MOUFFE, C. Feminismo, cidadania e política democrática radical. O regresso do político. Lisboa: Gradiva, 1996. p. 101-120.

MOVIMENTO DE MULHERES CAMPONESAS - MMC. Movimento de Mulheres Agricultoras: 21 anos de organização em Santa Catarina. Chapecó: MMC, 2004.

NICHOLSON, L. Interpretando o gênero. Estudos Feministas, Florianópolis, v. 8, n. 2, p. 9 , jan. 2000.

OLIVEIRA, ROSISKA DARCY DE. Elogio da diferença; o feminino emergente. 2a. Ed. Sáo Paulo: Brasiliense, 1992. 150p.

PAULILO, M. I. Intelectuais \& militantes e as possibilidades de diálogo. Revista de Estudos Feministas, v. 18, n. 3, p. 927-940, 2010.

.; MATIAS, I. A. Mulheres e eucalipto: fertilidade e aridez. Ambiente Brasil, 2006. Disponível em: <http://ambientebrasil.com.br>. Acesso em: 21 dez. 2016.

PINTO, C. R. Movimentos sociais: espaços privilegiados da mulher enquanto sujeito político. In: COSTA, A. O.; BRUSCHINI, C. (Org.). Uma questáo de gênero. Rio de Janeiro: Rosa dos Ventos; São Paulo: Fundação Carlos Chagas, 1999.

PORTOLÉS, A. O. Debates sobre el género. In: AMORÓS, C.; MIGUEL, A. de (Ed.). 2. ed. Teoría feminista de la ilustración a la globalización: de los derechos de género al multiculturalismo. Madrid: Minerva Ediciones, 2007. p. 13-60.

RODRÍGUEZ MAGDA, R. M. El placer del simulacro: feminismos y transmodernidad In: FEMENÍAS, M. L. Perfiles del feminismo latino-americanos: Vol. 3. Buenos Aires: Catálogos, 2007. p. 139-160.

ROSA, M. C. Sociologias do Sul: ensaio bibliográfico sobre limites e perspectivas de um campo emergente. Civitas, v. 4, n. 1. Porto Alegre, p. 43-65, jan./abr. 2014.

SAFFIOTI, H. I. B. A mulher na sociedade de classes: mito e realidade. São Paulo: Quatro Artes, 1969. .; ___. São Paulo: Quatro Artes, 1978.

SÁNCHEZ, C.; BÉLTRAN, E.; ALVAREZ, S. Feminismo liberal, radical e socialista. In: BÉLTRAN, E.; MAQUIERA, V.; ALVAREZ, S.; SÁNCHEZ, C. (Ed.). 2. ed. Feminismos: debates teóricos contemporâneos. Madrid: Alianza Editorial, 2005. p. 75-125.

SARTORI, A.; SANTOS, A.; SILVA, C. Tecendo fios entre o feminismo latino-americano descolonial e os estudos pós-coloniais latino-americanos. Revista de Educaçáo Universidade Federal de Pernambuco, Caruaru, v. 1, n. 1, p. 86-98, 2015. 
SCOTT, J. W. Gênero: uma categoria útil de análise. Educação e Realidade, Porto Alegre, v. 16 , n. 2, p. 5-22, 1990.

Experiência. In: SILVA; LAGO; RAMOS (Org.) Falas de gênero. Florianópolis: Ed. Mulheres, 1999. p. 21-55.

. "La querele des femmes" no final do século XX. Revista de Estudos Feministas, v. 9, n. 2, p. 367-388, 2001.

SENDON DE LEON, V. Mas ala de Itaca. Barcelona: Icaria, 1988.

SHIVA, V.; MIES, M. Ecofeminismo. Lisboa: Instituto Piaget, 1997.

TEMPO SOCIAL: Revista de Sociologia da USP - Faculdade de Filosofia, Letras e Ciências Humanas, v. 6, n. 1, São Paulo, 2014.

VALCÁRCEL, A. Feminismo en el mundo global. 3. ed. Madrid: Ediciones Cátedra; Universitat de València; Instituto de la Mujer, 2008.

\section{What Type of Feminism is this that Grows in the Vegetable Garden?}

\section{Abstract}

This paper seeks to demonstrate the need to adapt feminist theories if they are to account for feminism such as is part of the ideals of the Movimento de Mulheres Camponesas (MMC) (Peasant Women's Movement), an organization that has been active in Brazil since 1983, although it only defined itself as feminist in 2010. The type of evolutionism usually underlying comparisons of the countryside and the city must be shunned. Rodríguez Magda's concept of "transmodernity" (2007) proves useful in that it is not based on evolutionist notions of feminism, but rather holds that elements of different strands of feminism, old and new, are combined in the current forms. Magda does not see these recent forms as more accurate than previous ones, preferring to address the "useful fictions" that mobilize movements and are therefore "real". To trace these "useful fictions", a historical review of the strands which have contributed to the feminism of rural women is undertaken. Scott (1999) concept of "experience" and Geertz (2003) concepts of "experience-near" and "experience-distant" are proposed to explain the practice of these militant women. We believe that the full investigation can only be completed after a theoretical-methodological discussion focused on the research problem.

Keywords: Gender. Feminism. Rural women. Rural social movements. 